\title{
INVISIBLE CONSEQUENCES: THE HEALTH HAZARDS OF "WOMEN'S WORK" IN NEW ZEALAND
}

\author{
Dawn Duncan*
}

Gordon Anderson has written extensively on the changes in New Zealand's labour laws that have occurred since the late 1960s, and the consequences of these changes for workers. This period saw the narrowing and individualising of work health and safety, the separation of health and safety from other areas of employment relations and the workers' compensation functions of the Accident Compensation Corporation (ACC) scheme. This article explores one of the largely invisible consequences of these shifts, arguing that gaps have emerged between these areas of law, and these gaps fall disproportionately over the types of work that women typically perform. This article outlines the current gaps in the law and identifies the areas in need of reform.

\section{INTRODUCTION}

In Reconstructing New Zealand's Labour Law: Consensus or Divergence ${ }^{1}$ Gordon Anderson tracks the significant shifts that occurred in the laws governing employment relations in New Zealand, moving from the award system to the individualistic contractualism of the Employment Contracts Act 1991 and to the stable, but perhaps less than ideal, consensus under the Employment Relations Act 2000 (ER Act). ${ }^{2}$ New Zealand is perhaps again at a turning point in the regulation of the employment relationship, with the Labour-led Government signalling potentially dramatic shifts in wage setting mechanisms. ${ }^{3}$ One area currently receiving public and political attention is the treatment of workers

* Dawn Duncan is a lecturer at The University of Otago Faculty of Law and former PhD student of Gordon Anderson.

1 Gordon Anderson Reconstructing New Zealand's Labour Law: Consensus or Divergence? (Victoria University Press, Wellington, 2011).

2 See discussion in Anderson, above $n 1$.

3 The Labour Party's 2017 Election Platform included the introduction of Fair Pay Agreements: Labour Party "Backing fair pay and conditions" <www.labour.org.nz>. The policy states: "Fair Pay Agreements (FPAs) will be agreed by businesses within an industry and the unions representing workers within that industry. FPAs will set basic standards for pay and other employment conditions within an industry, according to factors including job type and experience." The new Government also appointed a working group to develop 
in typically female occupations, particularly after the 2014 Court of Appeal decision in Terranova Homes and Care Ltd v Service and Food Workers Union Nga Ringa Tota Inc. ${ }^{4}$ The previous National Government appointed the Joint Working Group on Pay Equity Principles, ${ }^{5}$ then negotiated a significant pay settlement with the unions representing caregivers and other support workers, ${ }^{6}$ before introducing legislation to create a new process for pay equity bargaining. The current Prime Minister, the Rt Hon Jacinda Ardern, declared that her government "will not rest until we have pay equity in New Zealand", ${ }^{7}$ extending the pay equity settlement to other groups of workers in care and support roles and introducing reform legislation of its own. Further, at the time of writing, New Zealand is experiencing what has been described in the media as the most significant resurgence in strikes in 30 years, including strikes by the nation's teachers and nurses. ${ }^{8}$

Achieving equal recognition for workers in these occupations goes beyond just pay and it is timely to examine the treatment of these workers under New Zealand's health and safety and workers' compensation laws. Drawing on doctoral research conducted under Gordon Anderson's supervision, this article will argue that people performing work in typically female occupations are receiving significantly less favourable treatment under New Zealand's health and safety and workers' compensation laws compared to workers in other occupations and this is an area in need of urgent reform.

\section{NEW ZEALAND'S REGULATION OF WORK AND HEALTH}

There are three primary pieces of legislation that relate to workers' health in New Zealand. The Accident Compensation Act 2001 (ACA), the Health and Safety at Work Act 2015 (HSWA) and the ER Act. None of these statutes make an explicit distinction between men and women. The problem lies in the different legal treatment of work-related health conditions, with the health conditions most likely to affect workers in typically female occupations receiving less favourable treatment. If we start our analysis with the work being performed and the hazards of that work, we can see a clearer picture emerging of whose work is excluded. New Zealand's labour market remains highly segregated by

a proposal for such agreements that has reported back: Fair Pay Agreements: Supporting workers and firms to drive productivity growth and share the benefits - Recommendations from the Fair Pay Agreement Working Group, 2018 (20 December 2018).

4 Terranova Homes and Care Ltd v Service and Food Workers Union Nga Ringa Tota Inc [2014] NZSC 196, [2015] 2 NZLR 437.

5 Recommendations of the Joint Working Group on Pay Equity Principles (25 May 2016).

6 See Ministry of Health "Pay equity settlements" (28 March 2018) <www.health.govt.nz> for settlement details.

7 Lincoln Tan "Ardern: Labour will not rest until there is pay equity" The New Zealand Herald (online ed, Auckland, 12 August 2017).

8 Alex Brae "Fact check: Has there been more striking in 9 months of Labour than 9 years of National?" (26 June 2018) The Spinoff <https://thespinoff.co.nz>. 
gender, meaning that male and female workers tend to cluster in particular occupations. ${ }^{9}$ Different types of work entail exposure to different types of hazards and result in different patterns of workrelated health problems. ${ }^{10}$

Looking at the international research and the data available from workers' compensation schemes in other jurisdictions (the lack of New Zealand data is discussed further below), it is clear that the work that women typically perform (eg teaching, caregiving, healthcare and administration) tends to be associated with exposure to psychosocial hazards such as bullying, harassment, occupational violence, workload stress and care fatigue. ${ }^{11}$ These hazards are associated with increased rates of chronic stress-related illnesses, including mental illnesses such as depression and anxiety. ${ }^{12}$ Psychosocial hazards and work stress-related illnesses are treated very differently from other hazards and work-related health problems under New Zealand law. To understand how this difference in treatment operates in practice, it is useful to compare two groups of workers, one performing work in a typically male occupation, such as a builder, and one performing work in a typically female occupation, such as a social worker. ${ }^{13}$

Each job has a particular set of health risks associated with the work being performed. The risks associated with building work are more likely to involve accidental physical injury, for example falls from height, crushing injuries, trench or scaffold collapse, electric shock and slips, trips and falls. ${ }^{14}$ The job of a social worker tends to have a risk profile associated with occupational violence (eg being assaulted by clients), compassion fatigue, traumatic stress, workload stress and burnout. ${ }^{15}$ Builders

9 Statistics New Zealand and Ministry for Women "Women at Work: 1991-2013" (20 October 2015) $<$ http://archive.stats.govt.nz>.

10 See Amanda Eng and others "Gender Differences in Occupational Exposure Patterns" (2011) 68 Occupational Environmental Medicine 888.

11 Joanna Wieclaw and others "Work related violence and threats and the risk of depression and stress disorders" (2006) 60 J Epidemiol Community Health 771; John Rodwell and Defne Demir "Psychological consequences of bullying for hospital and aged care nurses" (2012) 59 International Nursing Review 539; and André Brouwers and Welko Tomic "A longitudinal study of teacher burnout and perceived self-efficacy in classroom management" (2000) 16 Teaching and Teacher Education 239.

12 Safe Work Australia Work-Related Mental Disorders Profile 2015 (December 2015).

13 Statistics New Zealand and Ministry for Women, above n 9: men make up 98 per cent of people employed as builders. Women make up approximately 85 per cent of social workers. See also Rannveig Dahle "Social work: A history of gender and class in the profession" (2012) 12 Ephemera: Theory \& Politics in Organization 309; and Grace Khunou, Roshini Pillay and Angela Nethononda "Social Work is 'Women's Work': An Analysis of Social Work Student's Perceptions of Gender as a Career Choice Determinant" (2012) 24 The Social Work Practitioner-Researcher 120.

14 WorkSafe "Building and construction: Absolutely essential toolkit" (14 September 2017) $<$ https://worksafe.govt.nz>.

15 Brian E Bride and Charles R Figley "The Fatigue of Compassionate Social Workers: An Introduction to the Special Issue on Compassion Fatigue" (2007) 35 Clinical Social Work Journal 151; April Naturale 
do, of course, face some risk of stress-related illness. Likewise, social workers do have some risk of accidental physical injury. However, in general, building work carries a much higher risk of accidental physical injury, and social work carries a much higher risk of developing stress-related illnesses. A builder with a broken leg as a result of scaffolding collapse, being the type of injury a builder is likely to suffer at work, is treated very differently from a social worker that develops depression from emotional fatigue, being the type of illness a social worker is likely to develop through work.

\section{THE GAPS IN ACC COVER}

One of the most important differences in legal treatment is access to compensation, treatment and rehabilitation under the ACA. The ACC scheme is unique to New Zealand and has a unique set of coverage problems when compared to workers' compensation schemes in other jurisdictions. As set out more fully elsewhere, the ACC scheme has had a difficult 50 years since its inception in the 1967 Woodhouse Report. ${ }^{16}$ The ACC scheme performs the primary workers compensation function in New Zealand, but, unlike other countries, it incorporates claims for work-related injury and illness within a wider national compensation scheme, which revolves around the problematic concept of "accident". ${ }^{17}$ Unlike the workers' compensation scheme tests in other countries, which compensate "workers", as defined where they suffer health conditions sufficiently related to work, the ACC scheme has a complex layering of multiple distinct tests of causal connection based loosely around outdated diagnostic categories. ${ }^{18}$

The first layer of cover is s 25, which covers "accidents," defined as "a specific event or a series of events, other than a gradual process" that: ${ }^{19}$

(i) involves the application of a force (including gravity), or resistance, external to the human body; or

(ii) involves the sudden movement of the body to avoid a force (including gravity), or resistance, external to the body; or

(iii) involves a twisting movement of the body...

"Secondary Traumatic Stress in Social Workers Responding to Disasters: Reports from the Field" (2007) 35 Clinical Social Work Journal 173; Chris Lloyd, Robert King and Lesly Chenoweth "Social work, stress and burnout: A review" (2002) 11 Journal of Mental Health 255; and Annie Fahy "The Unbearable Fatigue of Compassion: Notes from a Substance Abuse Counselor Who Dreams of Working at Starbucks" (2007) 35 Clinical Social Work Journal 199.

16 Dawn Duncan "ACC and Workers' Health: Compensation, Compromises and Consequences" in Gordon Anderson and others (eds) Transforming Workplace Relations in New Zealand 1976-2016 (Victoria University Press, Wellington, 2017) 230. See also Compensation for Personal Injury in New Zealand: Report of the Royal Commission of Inquiry (Government Printer, December 1967).

17 Duncan, above n 16.

18 Duncan, above n 16, at 231-239.

19 Accident Compensation Act 2001 [ACA], s 25(1)(a). 
The majority of slips, trips, falls, crushing, lacerations and deglovings fall within this definition. Workers with injuries that fall within the definition of accident are not required to establish any causal connection to work to have an entitlement. The builder in our example above would only need to show he suffered a broken leg to have cover under the scheme. ACC cover means that the builder would be entitled to treatment costs (including any X-rays, surgery or medication needed), compensation paid at the rate of 80 per cent of pre-incapacity weekly earnings after the first week (the first week paid for by the employer) and any vocational rehabilitation, return to work planning, support or assessment required. The social worker with depression would fall outside this definition.

If a worker's injuries fall outside the scope of s 25 , there is a second tier of cover, provided by s 30 and the occupational diseases schedule, ${ }^{20}$ both of which pose significant problems for workers in typically female occupations, like our social worker. The occupational diseases schedule provides a short list of particular diseases that have cover, each with a particular test of causation. For example, "[p]neumoconioses caused by sclerogenetic mineral dust (silicosis, anthraco-silicosis, asbestosis) and silico-tuberculosis, provided that silicosis is an essential factor in causing the resultant incapacity or death" or "[a]ngiosarcoma of the liver diagnosed as caused by vinyl chloride monomer." ${ }^{21}$ Conditions involving exposure to one of the identified substances are either given a specific test, for example, "[b]ladder carcinoma diagnosed as caused by 2-naphthylamine, benzidine, 4-aminobiphenyl, N, NBis (2-chloroethyl)-2-naphthylamine, other aromatic amines, or poly-cyclic aromatic hydrocarbons" 22 or the test is framed as "diseases of a type generally accepted by the medical profession as caused by..." and then the given substance. ${ }^{23}$

The schedule adopts a very "diagnosis specific" style of drafting and confines cover to what are traditionally considered "occupational" conditions. The schedule was originally based on the list of occupational diseases set out in International Labour Organization (ILO) Convention 42, the Workmen's Compensation (Occupational Diseases) Convention 1934, which New Zealand was a signatory to, but then failed to ratify subsequent amendments. The schedule contains what might be thought of as the classic occupational diseases of the early to mid-20th century, typically those that were the focus of union campaigning, such as lead or arsenic poisoning, silicosis, a limited range of diseases from handling animals or carcasses and a limited range of diseases from inhaling toxic substance containing dusts or fumes. ${ }^{24}$ The occupational diseases schedule is a product of its history

20 See sch 2.

21 Schedule 2, cls 1 and 21.

22 Schedule 2, cl 33

23 See for example sch 2 , cls 3 and 4.

24 J Leigh "History of occupational disease recognition and control" (2007) 23 J Occup Health and Safety - Aust NZ 519 . 
and as a result the diseases listed on the schedule are substantially more likely to occur in traditional 20th century male occupations.

There has generally been less research into women's occupational health and the health risks of work in female-dominated occupations. ${ }^{25}$ The occupational health of women is an area of wider neglect internationally, with occupational disease studies often limited to male participants. ${ }^{26}$ A paper prepared for the Global Commission on Women's Health highlighted the particular problems of data collection and presentation when it comes to women's occupational health, with health problems failing to be captured or obscured by the aggregation methods used in the research. ${ }^{27}$ What this means is that even when a condition looks to be prima facie covered by the ACC scheme, such as where there is exposure to a long established schedule-listed substance, workers in newer types of work struggle to obtain cover. For example, in Purdie v Accident Compensation Corporation the claimant sought cover for sceleroderma (an extremely rare skin condition). ${ }^{28}$ She argued it was caused by exposure to the solvents xylene and toluene (derivatives of benzene). Diseases arising from exposure to toxic derivatives of benzene and its homologues are included in the schedule, but exposure has traditionally occurred in older occupations and resulted in a different set of diagnoses. Given the low incidence of the claimant's particular disease (19 per million in population) there were only a few studies, meaning there was only "weak evidence" and the link was "not yet generally accepted by the medical profession", although no alternative causes could be suggested for the claimant's rare disease. $^{29}$

If the worker's condition is excluded from the schedule they may fall within the test in s 30 , which provides for any other gradual process diseases or infections, except mental health problems or those arising from "non-physical stress" as will be discussed further below. ${ }^{30}$ According to s 30(2), the worker would need to show:

25 See Lado Ruzicka "Issues in Occupational Mortality of Women" in Penny Kane (ed) Women and Occupational Health (World Health Organization, Geneva, 1999) 26; Karen Messing and Jeanne Megar Stellman "Understanding Occupational Disease in Women Workers" in Penny Kane (ed) Women and Occupational Health (World Health Organisation, Geneva, 1999) 19; and Karen Messing and Jeanne Mager Stellman "Sex, gender and women's occupational health: The importance of considering mechanism" (2006) 101 Environmental Research 149.

26 Isabelle Niedhammer and others "How is sex considered in recent epidemiological publications on occupational risks?" (2000) 57 Occup Environ Med 521.

27 Ruzicka, above n 25; and International Labour Organization "Gender and Occupational Safety and Health" $<$ www.ilo.org/safework>.

28 Purdie v Accident Compensation Corporation [2010] DC Wellington AI 111/08, 1 February 2010.

29 At [9]-[19].

30 ACA, s 30(5)(a). 
(a) the person-

(i) performs an employment task that has a particular property or characteristic; or

(ii) is employed in an environment that has a particular property or characteristic; and

(b) the particular property or characteristic-

(i) causes, or contributes to the cause of, the personal injury; and

(ii) is not found to any material extent in the non-employment activities or environment of the person; and

(iii) may or may not be present throughout the whole of the person's employment; and

(c) the risk of suffering the personal injury-

(i) is significantly greater for persons who perform the employment task than for persons who do not perform it; or

(ii) is significantly greater for persons who are employed in that type of environment than for persons who are not.

As with the schedule, s 30 is largely formulated to cover an "occupational disease," as thought of in the mid-20th century, rather than a disease that can be shown to have been caused by the particular person's work. The difference between an "occupational disease" and a disease caused by work, is an important one. "Occupational disease" is often a contested and politically won label, representing the acceptance of the condition as presumptively and largely exclusively caused by a work task or exposure. The disease itself takes on the status of being "occupational". In reality, there is rarely a way to distinguish between occupational and non-occupational diseases in blood tests or under a microscope, and the status of the disease impacts on who receives the diagnosis. A leading textbook in occupational medicine explains this, stating: ${ }^{31}$

There is a widely held belief...that diseases of occupational or environmental origin are both rare and distinctive. In reality, diseases caused by work and ambient environment are neither rare nor often distinctive in their clinical presentation and laboratory findings. Most occupational diseases, such as occupational cancers, not only resemble diseases caused by other factors but are otherwise indistinguishable except by careful documentation of history of a relevant exposure. Other occupational and environmental diseases, like asthma or dermatitis, may be distinguished clinically only through obtaining an exposure history, with or without specialised testing, which presupposes high suspicion for the diagnosis.

31 Mark C Cullen, Linda Rosenstock and Edwin W Kilbourne "Introduction to Occupational and Environmental Medicine" in Linda Rosenstock and others (eds) Textbook of Clinical Occupational and Environmental Medicine (2nd ed, Elsevier Saunders, Philadelphia, 2005) 3 at 3. 
Establishing the occupational status of a disease can be difficult for any worker but is especially difficult for workers in female-dominated occupations. Much of the work in female-dominated occupations involves tasks that are not unique to paid work, such as caregiving. Where a disease arises from tasks that are not done solely or primarily in paid work the disease is unlikely to be viewed as "occupational". The fact that workers may also be performing the same mental and emotional tasks outside of work makes establishing the "exclusiveness" of a work-related cause, as required under the current drafting of s 30, effectively impossible. Section 30(2)(b)(ii) of the ACA requires that the "particular property or characteristic" of the work alleged to have caused the illness "not [be] found to any material extent in the non-employment activities or environment of the person". It would be rare for a person working in a caring role to be able to show they were caring for others solely in a work context.

The health conditions most likely to affect workers in female dominated occupations are also likely to be excluded under s 30(5) as arising from "non-physical stress". The social worker in our example above would be excluded from cover, even if she could meet the four-part test in s 30(2). While this blanket exclusion affects any workers who develop a chronic mental illness or work stressrelated health problem, the impact is most acute for workers whose jobs place them at greater risk of developing these conditions. The effect is likely to be particularly significant for people in occupations in health care, education, administration and many service roles, who, looking to the Australian statistics, make up the majority of work-related mental illness and stress-related illness claims. ${ }^{32}$

The final two categories of cover for work-related health problems are provided in ss 21B and 28, which cover a narrow range of mental conditions arising from witnessing a traumatic event and an impossibly small number of heart attacks. The cover of cardiovascular diseases under s 28 is discussed more fully elsewhere. ${ }^{33}$ Section $21 \mathrm{~B}$ provides cover where "mental injury is caused by a single event" in particular circumstances. ${ }^{34} \mathrm{~A}$ person is required to experience the event directly and the event is required to be "an event that could reasonably be expected to cause mental injury to people generally". ${ }^{35}$ A person "experiences, sees, or hears an event directly" if they are involved in, or witnesses the event, and are "in close physical proximity to the event at the time it occurs". ${ }^{36}$ This section was inserted following lobbying by transport unions that had members affected by transport accidents involving pedestrians or suicidal people. This section does not cover chronic stress-related

32 Safe Work Australia Work-Related Mental Disorders Profile 2015, above n 12. See also Safe Work Australia The Incidence of Accepted Workers' Compensation Claims for Mental Stress in Australia (April 2013) at 9.

33 See for example Dawn Duncan "A Battle for Hearts and Minds: New Zealand's Legal Response to WorkStress-Related Depression and Cardiovascular Disease" (2018) 43(3) NZJER 3.

34 Section 21B(1)(b).

35 Section $21 \mathrm{~B}(2)(\mathrm{b})$.

36 Section $21 B(5)(a)$ and (b). 
mental illness, such as that resulting from bullying, sexual or other harassment, burnout or care fatigue most likely to affect workers in typically female occupations.

For example, in $K B v$ Accident Compensation Corporation the case involved a claim made by a police officer attending a particularly distressing suicide who had to counsel the family, which she alleged caused her condition. ${ }^{37}$ The Court found that "the appellant ha[d] experienced a significant number of events in the course of her work"38 and declined cover, holding that for an event to meet the requirements of s $21 \mathrm{~B}$ it: ${ }^{39}$

... must be one that is in effect a one-off event, and which results in the more or less immediate onset of the factors involved in the medical condition of Post-Traumatic Stress Disorder...

This would exclude the social worker in our example, as well as a significant number of other workers like nurses and carers who would rarely be fortunate enough to have only one traumatic event in the course of their employment. In OCS Ltd $v$ TW a claim was made for a mental health problem resulting from a pattern of bullying and harassment which culminated in an incident of minor assault. ${ }^{40}$ The Court decided that such situations fell outside the mischief that s 21B was introduced to remedy and the incident complained of had to be sudden rather than occurring at the end of a pattern of bullying behaviour. ${ }^{41}$ Looking to the Australian statistics, workers in typically female occupations are significantly more likely to make claims of bullying or harassment. ${ }^{42}$ There has been some discussion of the impact of the 2016 case of MC $v$ Accident Compensation Corporation, ${ }^{43}$ offering some hope to workers whose trauma does not fit neatly in to a single event. In this case the claimant suffered a series of traumatic events in the course of employment as a police officer and in active combat in Afghanistan. The judge in this case took a wider view of the single incident requirements. Even if the decision in MC v Accident Compensation Corporation does widen the approach taken to s 21B, it is still a very narrow category of cover, leaving the vast majority of work stress-related mental illnesses outside the scope of ACC cover.

If we return to the builder and social worker in our example, the builder who suffered a broken leg would likely receive ACC cover, meaning they would be entitled to treatment costs, earnings compensation and other support. If the social worker in our example developed depression as a result

37 KB v Accident Compensation Corporation [2013] NZACC 41.

38 At [24].

39 At [25].

40 OCS Ltd v TW [2013] NZACC 177.

41 At [80]-[82].

42 Safe Work Australia Work-Related Mental Disorders Profile 2015, above n 12. See also Safe Work Australia The Incidence of Accepted Workers' Compensation Claims for Mental Stress in Australia , above n 32.

43 MC v Accident Compensation Corporation [2016] NZACC 264. 
of her job, she would not receive any such entitlements. If the social worker broke a leg at work, the injury would fall under "accident" under s 25 and the person would, of course, receive the same treatment as the builder would. The problem is that the risk of the social worker suffering this type of injury at work is comparatively low and the risk of suffering an excluded health problem is comparatively high. The exclusion of certain work-related conditions has a negative impact on all workers, not only preventing affected workers from obtaining treatment, rehabilitation and compensation, but potentially exacerbating existing stigmas about the "realness" or "worthiness" of mental health problems. The impact of these exclusions is arguably most significant for those people who perform work with risk profiles involving a relatively higher risk of developing such health problems, which disproportionately include typically female occupations.

\section{THE SIZE OF THE PROBLEM}

It is difficult to know exactly how many New Zealand workers in typically female occupations are developing the health conditions excluded from ACC cover or the full impact of this exclusion. In New Zealand, occupational illness and injury statistics come primarily from ACC administrative data and as there is no cover for these conditions, there is no resulting data. The lack of data creates a cycle of invisibility. If the health problems affecting workers performing this type of work are excluded from cover, then, of course the data on work-related health problems in New Zealand also exclude these conditions. The National Occupational Health and Safety Advisory Committee, issued Technical Report 13, Women's Occupational Health and Safety in New Zealand, concluding: ${ }^{44}$

... [v]ery little is known about women's OHS. The lack of research in exposures and health effects associated with women's jobs have enforced the widespread assumption that women's jobs are safe, thus perpetuating the lack of knowledge and action on women's occupational ill health.

Helpfully, there are Australian statistics that may provide some guidance. The Australian workers' compensation data (chronic work-related mental health problems are compensated under these schemes) highlight that women performing typically female work are significantly more likely to make mental health claims than men. In the 2013 Report of Safe Work Australia, The Incidence of Accepted Workers' Compensation Claims for Mental Stress in Australia, women accounted for 58.6 per cent of mental stress claims while making up only 33.6 per cent of total workplace injury claims. ${ }^{45}$ The highest number of claims was for "work pressure" related illness. Harassment and bullying had the second highest number of claims, and then "exposure to workplace or occupational violence". ${ }^{46}$

44 National Occupational Health and Safety Advisory Committee Women's Occupational Health and Safety in New Zealand (NOSHAC Technical Report 13, 2009) at iv.

45 Safe Work Australia The Incidence of Accepted Workers' Compensation Claims for Mental Stress in Australia, above at n 32, at 9 .

46 At 8 . 
Claims increased with worker age, with women aged 50-54 making the most claims. ${ }^{47}$ When analysed per hour worked: ${ }^{48}$

... women were three times more likely than men to have a claim caused by [w]ork-related harassment

\&/or workplace bullying (15 claims per 100 million hours worked compared with 5) and [were] twice as

likely to have a claim caused by [e]xposure to workplace or occupational violence.

It is not the gender of the worker that makes them more likely to develop mental health problems, but the fact the workers are performing jobs that involve greater interaction with people. Safe Work Australia's Director of Data and Analysis emphasised that the "key determinant for work-related disease and injury is occupation rather than gender". ${ }^{49}$ When analysed on a per hour worked basis, male teachers, nurses and carers had about the same number of claims as their female colleagues. ${ }^{50}$ In Australia "64\% of mental disorder claims arise from 4 out of 19 industry divisions". ${ }^{51}$ Health care, social assistance and public administration each made up 21 per cent of claims, with education and training a further 14 per cent: ${ }^{52}$

The types of occupations of workers receiving compensation for a work-related mental disorder tend to

be those who work in occupations which involve high levels of interaction with other people, often

rendering a service to the public and often doing their job in difficult and challenging circumstances.

Although there are no New Zealand figures, the former Department of Labour commissioned a study, Understanding Stress and Bullying in New Zealand Workplaces, which provided a snapshot of the extent to which stress and bullying were a problem. ${ }^{53}$ The survey results indicated "the prevalence [of stress and bullying] was relatively high compared to international findings". ${ }^{54}$ The significant costs associated with poor mental health in New Zealand has also been highlighted in the He Ara Oranga: Report of the Government Inquiry in to Mental Health and Addiction, ${ }^{55}$ and the 2018

47 At 10

48 At 9 (italics omitted).

49 Safe Work Australia "International Women's Day: Reflecting on women's health and safety in the workplace" (2016) <www.safeworkaustralia.gov.au>.

50 Safe Work Australia Work-Related Mental Disorders Profile 2015, above n 12, at 11.

51 At 6 .

52 At 6.

53 Tim Bentley and others Understanding Stress and Bullying in New Zealand Workplaces: Final Report to the OH\&S Steering Committee (17 December 2009).

54 At i.

55 He Ara Oranga: Report of the Government Inquiry in to Mental Health and Addiction (November 2018). 
Organisation for Economic Co-operation and Development (OECD) Mental Health and Work: New Zealand report, which concluded: ${ }^{56}$

Given that the cost of serious mental health conditions is higher in New Zealand than in Australia, it can be concluded that the total cost of mental health to the New Zealand society is in the order of around 4$5 \%$ of GDP and thus at the top-end among OECD countries.

There is currently no ACC cover for New Zealand workers that are psychologically affected by harassment or bullying, whether sexual or otherwise, the chronic psychological effects of occupational violence or work stress-related mental or physical illnesses. It is reasonable to assume there are a considerable number of people working in typically female occupations, (as well as in other fields) left without compensation, rehabilitation or return to work support.

\section{$V$ THE CONSEQUENCES OF EXCLUSION FROM ACC}

The social worker suffering depression in our example could sue their employer for compensation. The New Zealand ACC scheme generally bars claims for compensation for personal injury, but workers can make claims where their conditions are excluded. ${ }^{57}$ The social worker could raise a personal grievance for unjustifiable disadvantage (the disadvantage being the employer's failure to meet their health and safety obligations), allege a breach of an implied term of the employment contract or potentially bring a tort claim for breach of statutory duty or negligence. A number of these cases have been brought following the Court of Appeal decision in Attorney-General $v$ Gilbert. ${ }^{58}$ These actions, however, require the employee to prove the employer's fault, which the New Zealand Court of Appeal has described as posing "formidable obstacles". 59 The more complex causal connections between work and the development of stress-related illnesses pose difficult evidential barriers to success in such claims. An employee is also required to bear the financial and emotional costs of bringing legal action, something rarely appealing to someone suffering from a work-related mental health problem and potentially without income.

If an employee does bring such a claim the remedies available are often unsuitable and the amount in compensation considerably less than available under the ACC scheme. For example, the most common way to bring such a case is using the personal grievances regime in the ER Act. The employee's personal grievance remedies are usually limited to the remedies of reimbursement of lost wages (generally capped at 12 weeks' ordinary time) and compensation for "humiliation, loss of dignity, and injury to the feelings" under s 123(1)(c)(i). Twelve weeks' wages may fall well short of the actual time needed to recover from many work stress-related illnesses, and the commonly called

56 OECD Mental Health and Work: New Zealand (2018) at 26.

57 ACA, s 317.

58 Attorney-General v Gilbert [2002] 2 NZLR 342 (CA).

59 At [83]. 
"hurt and humiliation" payment is not designed to provide for medical treatment, on-going income support for incapacity or rehabilitation. Most of these cases are likely resolved through the Employment Mediation Services, with sums recorded in confidential settlements, making it difficult to fully evaluate the impact of this option on worker outcomes. Generally, however, the sums agreed to in such cases are relatively small and unlikely to be equivalent to the compensation available under the ACC scheme for accidental physical injury, such as that available to the builder with a broken leg in our example.

If the worker is unsuccessful in their claim and they do not have health insurance that covers their particular health condition, they have only the benefit system or family to fall back on. In 2013, research was conducted into the socioeconomic impact of the difference in financial support between ACC and Work and Income (WINZ) on a group of people of a similar age and level of functional impairment. ${ }^{60}$ The study concluded that those in the illness group (not covered by ACC) had considerably poorer socio-economic outcomes, did not return to work as early, and were the most vulnerable for decline into poverty and ill health. ${ }^{61}$ The exclusion of such significant chronic work-related health conditions potentially leaves a large number of workers without support. Although difficult to establish without data, workers in typically female occupations are, as a result of the work they perform, more likely to be in this group, with potentially serious consequences for their health and economic wellbeing.

\section{A Lack of Health and Safety Policy and Enforcement Action}

The lack of data on the health conditions affecting workers in typically female occupations has a significant flow-on impact on occupational health and safety research, policy and intervention. If a problem is not visible in the official statistics, it is unlikely to receive government attention. New Zealand recently enacted the HSWA. The legislation was a response to New Zealand's poor record of occupational health and safety, highlighted in the Royal Commission on the Pike River Coal Mine Tragedy report and The Report of the Independent Taskforce on Workplace Health \& Safety. ${ }^{62} \mathrm{New}$ Zealand has a long history of neglecting the health impacts of work, especially those falling outside the definition of "accident" in s 25 of the ACA. This was highlighted by the Royal Commission on the Pike River Coal Mine Tragedy, the Independent Taskforce on Workplace Health and Safety and

60 Susan McAllister and others "Do different types of financial support after illness or injury affect socioeconomic outcomes? A natural experiment in New Zealand" (2013) 85 Social Science \& Medicine 93.

61 At 100 .

62 Graham Panckhurst, Stewart Bell and David Henry Royal Commission on the Pike River Coal Mine Tragedy: Volume 1 + Overview (October 2012); and Rob Jager and others The Report of the Independent Taskforce on Workplace Health \& Safety: He Korowai Whakaruruhau (April 2013). 
a number of other bodies. The Independent Taskforce on Health and Safety described New Zealand's response to chronic health problems as a "tragic paradox": 63

While New Zealand's acute harm and workplace safety statistics are woeful and rightly attract considerable attention, the much more damaging occupational health impacts of the workplace go almost completely under the radar.

Despite recognising the problems from the mid-1990s, successive governments have decided not to address the issues due to cost implications and policy difficulties. This pattern was sadly continued in the Working Safer reforms introduced under the previous National Government, with "occupational diseases" excluded from the current Working Safer national targets because this area was "more difficult to monitor". ${ }^{64}$ Excluding chronic work-related health problems from the targets has the potential to further sideline the health and safety needs of workers in typically female occupations. Where targets are set, funding and action tends to follow. For example, all of WorkSafe New Zealand's priority industries are typically male occupations, reflecting the focus on accidental injury and death rates. ${ }^{65}$ This article is not arguing against attention being given to these industries, New Zealand's death and injury rates in these areas are appallingly high and in need of urgent intervention. There is a risk however, given the lack of data and additional complexities of chronic health problems, that the health and safety needs of workers in typically female occupations will again fall to the bottom of the list.

WorkSafe has issued Healthy Work: WorkSafe's Strategic Plan for Work-Related Health 2016 to 2026, which acknowledges the problems associated with the neglect of chronic health problems and the urgent need to take action. ${ }^{66}$ There are significant challenges for WorkSafe to be able to achieve its goals in relation to work-related health problems, including the lack of reliable statistical information and a lack of suitable enforcement machinery to address psychosocial hazards. Despite recent reforms, the HSWA provides little enforcement machinery suitable to respond to the complex psychosocial hazards often present in typically female occupations. The HSWA is still very much Robens model legislation, and still contains many of the Robens model biases and assumptions. ${ }^{67}$ The

63 Jager and others, above n 62, at [43] (italics omitted).

64 Ministry of Business, Innovation and Employment Working Safer: Reducing work-related fatalities and serious injury by 2020 - Progress toward the target (March 2015) at 20.

65 WorkSafe Prosecution Policy (December 2016).

66 WorkSafe Healthy Work: WorkSafe's Strategic Plan for Work-Related Health 2016 to 2026 (August 2016).

67 The Robens Model refers to a model of health and safety regulation proposed in the Robens Report adopted in the United Kingdom, New Zealand and Australia. For discussion of the Robens model and its assumptions see Theo Nichols The Sociology of Industrial Injury (Mansell Publishing, London, 1997) at 2-3; Philip Bohle "Work Psychology and the Management of Occupational Health and Safety: An Overview" in Michael Quinlan (ed) Work and Health: The Origins, Management and Regulation of Occupational Illness (Macmillan, Melbourne, 1993) 57; William Breen Creighton, William Ford and Richard Mitchell Labour 
HSWA remains designed around this traditional picture of health and safety: male employees, performing primarily physical tasks, in mines, workshops and factories, working for large organisations with strong unions and exposed to the risks of accidental physical injury, and to a lesser extent hazardous substances.

New Zealand's health and safety legislation has, since 2004, included mental health within the definition of "harm", and bullying within the definition of "hazard", making clear that the primary duty imposed on employers extends to psychosocial hazards and the protection of their employees' mental health. ${ }^{68}$ However, there was little enforcement action taken beyond the case of Department of Labour v Nalder \& Biddle (Nelson) Ltd. ${ }^{69}$ The assumptions made in 2004, and repeated in the 2015 Act, were that the existing legislative tools and machinery, despite being designed to respond to accidental physical injury, are suitable for addressing psychosocial hazards. This has not, however, been shown to be the case in other countries. Australian research highlights that even when psychosocial hazards are expressly included within the primary duties of the legislation they remain "a marginal area of inspectorate activity". ${ }^{70}$ Psychosocial hazards "are commonly 'invisible' to traditional methods of workplace inspections,"71 and they are also more complex, time-consuming and resource-intensive to investigate. ${ }^{72}$

Returning to our example of the builder with a broken leg and the social worker with depression, the builder's broken leg would require the notification of WorkSafe under s 23(1)(a), potentially triggering an investigation by WorkSafe and possibly enforcement action. With the construction sector being a priority for WorkSafe, there is a good chance of regulator intervention. The social worker's depression does not require WorkSafe notification. In fact, the position of WorkSafe is to encourage the affected employee to address their concerns through discussion, take a personal grievance or attend mediation with their employer in the hope that they may be able to negotiate a safer workplace. ${ }^{73}$ Whereas the builder's work-related injury would likely trigger regulator interest and potentially enforcement action, the social worker is encouraged to try to resolve matters on their own, wearing the costs and further stress of doing so, while also potentially without income, having been excluded from compensation under ACC. Just as the personal grievance regime is a poor

Law: Text and Materials (2nd ed, Law Book, Sydney, 1993) at 1340; and HJ Glasbeek "Occupational Health and Safety Law: Criminal Law as a Political Tool" (1998) 11 AJLL 95 at 99.

68 Health and Safety in Employment Act 1992, s 2 definition of "hazard" and "harm" (now repealed).

69 Department of Labour v Nalder \& Biddle (Nelson) Ltd DC Nelson CRN 04042500, 13 April 2005.

70 Richard Johnstone, Michael Quinlan and Maria McNamara "OHS inspectors and psychosocial risk factors: Evidence from Australia" (2011) 49 Safety Science 547 at 556.

71 At 548 .

72 At 551 .

73 See the most recent statement in WorkSafe Bullying at Work: Advice for Workers (February 2017). 
substitute for a fair workers' compensation system, so too, is it a poor substitute for proper health and safety enforcement.

There are significant problems with WorkSafe encouraging this approach. Ensuring compliance with health and safety laws should not, as a matter of policy, be a task that falls to individual workers to try to negotiate in the context of confidential mediation. Both in terms of bargaining power and personal capacity, a worker with a stress-related mental illness is in a poor position to be able to negotiate any meaningful changes to health and safety in their workplace. Although there is no reliable data kept on this in New Zealand either, a significant proportion of stress-related illness claims are likely resolved in mediation with an agreed resignation and a confidential settlement, neither of which is likely to result in meaningful changes to conditions of work. Employers have little incentive to improve working conditions where there are few consequences for not doing so and there is a free mediation process to quietly resolve any issues that do arise at an individual level.

\section{THE ROLE OF UNIONS IN ACHIEVING EQUITY IN THIS AREA}

Unions representing workers in typically female occupations can, and do, take cases in this area, making worker health part of their wider organising campaigns and addressing hazardous working conditions through collective bargaining. ${ }^{74}$ There also seems to be a recent rise in the health and safety related industrial action in New Zealand, particularly in the health sector, with the New Zealand Resident Doctors' Association striking for rostering changes to address fatigue and burnout and the recent New Zealand Nurses Organisation strike action to address workloads and understaffing. On the back of union campaigns following the Pike River Mine disaster and in support of the passage of the HSWA, unions in New Zealand have been able to use worker health issues to organise members around working conditions and appeal to the public for support.

There are, however, limits on what New Zealand unions are able to do in responding to the health needs of the workforce through collective bargaining. Unions have always been forced to make tradeoffs in bargaining, and the complex and long-term health effects of problematic working conditions often fall behind immediate gains in wages. This pressure to trade off improvements to workers' longterm health in favour of wage increases is particularly so where unions are operating in a hostile political environment and fighting wider pressures on union density. As Anderson has identified in his research, many New Zealand unions collapsed in the wake of the 1991 Employment Contracts Act and those surviving have often struggled to regain membership base and bargaining power. ${ }^{75}$ It is also simply unfair for unions representing workers in typically female occupations to have to spend

74 For example, the New Zealand Nurses Organisation, Post Primary Teachers' Association and Public Service Association have made significant strides in responding to these issues in their collective employment agreements.

75 Anderson, above n 1, at 77. 
significant time and resources performing what is rightly the role of the regulator in enforcing the country's health and safety laws or plugging the gaps in the provision of workers' compensation. The HSWA and the ACA are intended to operate as a legal safety net, which should be operating to ensure the health and safety of all workers regardless of industry.

\section{CONCLUSION}

Much attention has been paid to the impact of occupational segregation on the pay rates of workers in typically female occupations following the Terranova decision. ${ }^{76}$ However, remarkably little attention has been given to the impact of occupational segregation on health and safety or to the less favourable treatment of workers in typically female occupations under New Zealand's accident compensation and health and safety laws. Starting with an analysis of the hazards of the work that people in typically female occupations perform, a clear pattern of health risks emerge. The health problems most likely to affect workers in these occupations are also the most likely to be excluded from ACC cover. While these exclusions potentially affect all New Zealand workers, the consequences are particularly significant for workers in typically female occupations because of the type of work most commonly performed. The lack of cover also results in a lack of statistical information, rendering the health problems of workers in these occupations less visible, with flow-on effects on health and safety policy and enforcement. Reforms are needed to New Zealand's health and safety and compensation laws to better meet the needs of workers in these occupations and ensure that all workers have legal protections designed for the hazards of the work that they are engaged to perform. 
